\title{
Total occlusion of left main coronary artery. Treatment and surgical aspects
}

\author{
SS Aboul-Hassan", I Szwedo, A Szymańska, P Kwinecki, R Cichoń \\ From 23rd World Congress of the World Society of Cardio-Thoracic Surgeons \\ Split, Croatia. 12-15 September 2013
}

\section{Background}

This study is to evaluate the early results treatment of patients with total occlusion of the left main coronary artery. Total occlusion of the left main coronary artery is a very rare finding in patients with acute coronary syndrome. In these cases, patients present various clinical symptoms, however the symptoms and the survival of these patients depend on the development of collaterals and adequate medical intervention.

\section{Methods}

Between January 2002 till May 2013, four patients with acute coronary syndrome caused by total occlusion of the left main coronary artery underwent emergent coronary artery bypass grafting(CABG). All patients presented chest pain, signs of cardiogenic shock with CK$\mathrm{MB}$ level above100 $\mathrm{ng} / \mathrm{ml}$ on admission. IABP was inserted and emergent PCI and consecutive surgery within $24 \mathrm{hrs}$ were performed. One patient out of the four underwent on-pump beating heart CABG, the rest of the patients underwent classical CABG with induced cardiac arrest using blood cardioplegia with maintained normothermia. Early postoperativeevaluation was performed in terms of: ejection fraction, bleedings, CK-MB level and deaths.

\section{Results}

Three patients, who underwent classical CABG with induced cardiac arrest using blood cardioplegia with maintained normothermia, survived, whereas patient who underwent on-pump beating heart CABG died in the post-operative period due to hemodynamic failure with an ineffective response to reanimation.

* Correspondence: s.aboulhassan@gmail.com

Heart Diseases Center MEDINET, Wroclaw, Poland

\section{Conclusion}

It is very difficult to treat such patients with acute coronary syndrome complicated with cardiogenic shock caused by total occlusion of left main coronary artery. Such patients could develop massive myocardial infarction and should be treated immediately with emergent PCI, IABP and emergent CABG within 24 hours.Onpump beating heart CABG is possible in these patients, however we recommend treating such highly risky patients by CABG with induced cardiac arrest using blood cardioplegia with maintained normothermia.

Published: 11 September 2013

doi:10.1186/1749-8090-8-S1-P111

Cite this article as: Aboul-Hassan et al:: Total occlusion of left main coronary artery. Treatment and surgical aspects. Journal of Cardiothoracic Surgery 2013 8(Suppl 1):P111.
Submit your next manuscript to BioMed Central and take full advantage of:

- Convenient online submission

- Thorough peer review

- No space constraints or color figure charges

- Immediate publication on acceptance

- Inclusion in PubMed, CAS, Scopus and Google Scholar

- Research which is freely available for redistribution
() Biomed Central

\section{Biomed Central}

(c) 2013 Aboul-Hassan et al; licensee BioMed Central Ltd. This is an Open Access article distributed under the terms of the Creative Commons Attribution License (http://creativecommons.org/licenses/by/2.0), which permits unrestricted use, distribution, and reproduction in any medium, provided the original work is properly cited. 